\title{
ILCEA
}

Revue de l'Institut des langues et cultures

d'Europe, Amérique, Afrique, Asie et Australie

46 | 2022

Refuges identitaires numériques

\section{La proyección del estado de ánimo a través de WhatsApp. Un estudio de las emociones desde la perspectiva de género}

Externalising Emotional States through WhatsApp. A Study of Emotions from a

Gender Perspective

La projection de l'état d'âme à travers WhatsApp. Une analyse des émotions dans une perspective de genre

\section{Carmen Romo Parra, Inmaculada Sánchez-Labella Martín y Teresa Vera Balanza}

\section{OpenEdition}

\section{Journals}

Edición electrónica

URL: https://journals.openedition.org/ilcea/14067

DOI: $10.4000 /$ ilcea. 14067

ISSN: 2101-0609

\section{Editor}

UGA Éditions/Université Grenoble Alpes

\section{Edición impresa}

ISBN: 978-2-37747-331-1

ISSN: $1639-6073$

\section{Referencia electrónica}

Carmen Romo Parra, Inmaculada Sánchez-Labella Martín y Teresa Vera Balanza, «La proyección del estado de ánimo a través de WhatsApp. Un estudio de las emociones desde la perspectiva de género», ILCEA [En línea], 46 | 2022, Publicado el 02 marzo 2022, consultado el 04 marzo 2022. URL: http://journals.openedition.org/ilcea/14067 ; DOI: https://doi.org/10.4000/ilcea.14067 


\title{
La proyección del estado de ánimo a través de WhatsApp. Un estudio de las emociones desde la perspectiva de género
}

\author{
Externalising Emotional States through WhatsApp. A Study of Emotions from a \\ Gender Perspective \\ La projection de l'état d'âme à travers WhatsApp. Une analyse des émotions dans \\ une perspective de genre
}

Carmen Romo Parra, Inmaculada Sánchez-Labella Martín y Teresa Vera Balanza

\section{Introducción}

1 En el entorno digital la tendencia es que las relaciones sociales, ya sean a nivel profesional o personal, hallen en la tecnología una vía de expresión. A sabiendas de que en este espacio las voces son múltiples, adquirir una identidad propia y diferencial resulta fundamental para el proceso de mostración ante los otros. Y es que, tal y como apuntan Aladro Vico, De la Fuente y Padilla (2012) y Cuesta Cambra y Gaspar Herrero (2013), nos hallamos en un contexto de acción e interacción donde impera la cultura de la imagen y la apariencia. Por tanto, crear o recrear una identidad en el medio digital resulta ser una necesidad para hacer saber públicamente el modo de ser de quién construye un perfil intencionado y previamente estudiado (Turkle, 2011).

2 En este contexto, entender las redes sociales como espacios tecnológicos nos lleva a repensarlas desde la perspectiva de la tecnología de género, acuñada por De Lauretis (1989), en tanto en cuanto interesa conocer cómo se crean los contenidos según «la representación del género y cómo estos son asimilados subjetivamente por los individuos a los que se dirige» (p. 20). El estudio del avance de la tecnología atendiendo 
a su dimensión de género ha sido fértil desde los años 70 del pasado siglo (Perdomo Reyes, 2016). Las aportaciones teóricas del tecnofeminismo han desvelado la posición de desventaja de las mujeres en este entorno en tanto que las tecnologías se revelan como productos socioculturales que reproducen las identidades tradicionales de género. El proceso de retroalimentación entre el desarrollo de las TIC y las prácticas sociales y culturales, no solo recrean la estratificación de género tradicional, también construyen nuevos espacios e imaginarios de jerarquización de poderes y saberes que sostienen la exclusión de las mujeres (Wajcman, 2006).

3 A pesar de que en estas páginas estamos planteando, desde la perspectiva de género, la confección de la identidad como una práctica frecuente entre los usuarios digitales, Moral Jiménez (2004) sostiene que «la identidad la (re)inventamos todos como instrumento para manejarnos nosotros mismos y para ordenar y entender comprehensivamente la realidad de la que formamos parte» (2004: 184). Así pues, en el marco del medio digital, en general, y las redes sociales digitales, en particular, (en adelante RSD), el individuo, a partir de un proceso de reconocimiento, conocimiento y reflexión, consigue mostrar una imagen con la que desea ser identificado, lo cual permite suplir u ocultar sus carencias personales reales (Cáceres Zapatero, Brändle Señán \& Ruiz San Román, 2017; Hogg \& Reid, 2006; Strano, 2008; Zhao, Grasmuck \& Martin, 2008). Así pues, para quien se expresa en las RSD resulta necesario transmitir una imagen personal acorde a las tendencias sociales, para, de este modo, conectar con el grupo.

4 Tras estos breves apuntes, se ha de comentar que son varios los trabajos publicados que, desde distintos enfoques, se centran en cómo los individuos en edad joven utilizan las RSD como plataformas que contribuyen a fraguar su propia identidad. Investigadores como Fernández Rodríguez y Gutiérrez Pequeño (2017), Araque Loreto et al. (2018), Pérez Torres, Pastor Ruiz y Abarrou Ben Boubaker (2018), Rubio Gañan (2020) y Segura Alarcón y Anguita Anguita (2017) estudian la construcción de la identidad adolescente influenciada por redes sociales como Facebook, YouTube e Instagram. En base a ello, autoras como González Ramírez y López Gracia (2018) afirman que «los adolescentes construyen su identidad digital según dos motivaciones fundamentales: el bienestar personal y psicológico y el bienestar social» (2018: 82). Asimismo, mientras que la publicación de Guzzo (2019) plantea como los jóvenes proyectan una identidad diferente según las RSD, en el estudio de Del Prete y Redon Pantoja (2020) se observa cómo la configuración de la identidad, en ocasiones, coarta la libertad del propio individuo que se dispone a ello, ya que está sujeta a exigencias del grupo de iguales que esperan determinadas imágenes y comportamientos.

$5 \quad$ Si bien los datos arrojados por este tipo de publicaciones se fundamentan en las redes sociales digitales, entendidas estas como espacios para crear, establecer y mantener relaciones con personas tanto conocidas como desconocidas, los estudios centrados en WhatsApp, como un canal usado para estar en contacto con un grupo cercano y conocido de iguales, son menos frecuentes. Aun así, y a pesar del frenesí que provocan las RSD, autoras como González Ramírez y López Gracia (2018), antes citadas, Kemp (2016) y los resultados arrojados por el Centro de Investigaciones Sociológicas (2016), demuestran que WhatsApp es la aplicación de mensajería instantánea más usada para interactuar con la red de contacto.

Dada la escasa literatura publicada acerca de WhatsApp, en este momento se especifica que esta investigación se sustenta en los estudios basados en las redes sociales digitales 
a modo de marco de referencia. Así, y con la intención de conocer el modo en que los individuos confeccionan y proyectan su identidad ante las personas conocidas, que ya tienen una imagen sobre ellos, el objetivo de este artículo se centra en analizar la forma en que los y las jóvenes manifiestan su identidad a través de su perfil de WhatsApp. Se comprobará cómo, según el género, reflejan sus emociones y estados de ánimo a través de las fotografías, frases y emoticonos que utilizan para confeccionar sus perfiles.

\section{La imagen representada como unidad de expresión en WhatsApp}

El modo de reflejar la identidad, según el género, ha sido objeto de estudio en multitud de investigaciones. Concretamente, en torno a las imágenes femeninas ya en 1984 D'Amico publica que:

Las mujeres recibimos las pautas de nuestra identidad social a través de leyes, instituciones y costumbres y esto se materializa a través de la imagen y la palabra. La reprobación social, el «qué dirán», en cuanto nos apartamos de las condiciones establecidas, actúan como censores [...]. Las mujeres estamos condicionadas por las imágenes que nos muestran de otras mujeres, inducidas desde el exterior por la sociedad. (1984: 52)

Esta afirmación, planteada décadas atrás, hoy día adquiere más sentido, aún si cabe, si la tratamos desde el marco de las RSD, el uso de la telefonía móvil (Aguado, Martínez \& Tortajada, 2009; Sabater Fernández \& Bingen Fernández Alcalde, 2015), e incluso WhatsApp. Aun así, e independientemente de la plataforma de la que se trate y de la intencionalidad con la que se utilicen las imágenes (bien pueden ser concebidas como un recurso que permite mostrar y demostrar a los otros ser «el mejor del grupo» Campbell, 2006-, e incluso utilizadas con la intención de socializar, demostrando tener un estilo de vida activo), estas llevan consigo una reflexión sobre la veracidad de lo mostrado en lo que Hall, Pennington y Lueders (2013) denominan «grado de fiabilidad o "warranty" entre la identidad offline y online».

Si comparamos WhatsApp con las RSD, el primero se muestra como un espacio que restringe, en cierto modo, la exposición de la identidad. Si bien las redes sociales digitales poseen más posibilidades de expresión visual, incurriendo al mismo tiempo en la peligrosidad de «crear una identidad ficticia, potenciada por un factor de engaño, autoengaño o fantasía, y llegando incluso a provocar confusión entre lo íntimo, lo privado y lo público, lo cual deriva en conductas histriónicas y narcisistas deformando la realidad» (Echeburúa Odriozola, 2012: 438), WhatsApp, a simple vista, reduce este riesgo. En este sentido, y desde el enfoque de la proyección identitaria, López Cantos (2017) afirma que las fotografías empleadas en el perfil de esta plataforma de mensajería "sirven para la identificación primaria del usuario y se adjunta en cada uno de los mensajes, incluso lo referencia, aunque el usuario no esté online» (2017: 73). En WhatsApp, los usuarios cuentan con dos vías para poder proyectar quiénes son y qué hacen: la primera, a través de la publicación de una imagen o fotografía en el perfil, con la opción de acompañarla de una frase breve más iconos; la segunda, mediante la opción «Estados». Esta posibilidad permite compartir con los contactos de la agenda telefónica imágenes y vídeos que cuentan con una duración de $24 \mathrm{~h}$, pues pasado este tiempo desde su publicación el contenido desaparece. Aun así, y a pesar de estas fórmulas, quien delimita el modo de exponerse no es la propia aplicación, sino más bien el grupo que observa. Y es que, «aunque los otros ven como normal que nos comportemos y representemos de manera diferente en distintas situaciones» (Renau, 
Oberst \& Carbonell, 2013: 166), en la interacción con conocidos/as se imponen las regulaciones sociales, por lo que el modo de comportarse cambia según con quien se interactúa. Resulta evidente, por tanto, que ante quienes nos conocen las imágenes empleadas son más fieles a la realidad. A este respecto, el estudio de López Cantos (2017) sobre las fotografías empleadas en WhatsApp muestra que «las más valoradas son las de rostro neutro, familiares y de pareja, sin embargo, las que se consideran más fieles y garantistas son las que representan situaciones sociales» (2017: 85). Pero las imágenes no solo muestran modos de ser y hacer, sino que, al mismo tiempo, transmiten emociones y manifiestan un estado de ánimo; que en el caso de WhatsApp se completa con las frases o textos breves y emoticonos que acompañan a las fotografías de perfil.

\section{Manifestación y efecto de las emociones representadas}

10 Según Illouz (2009), el estudio de las emociones es abordado desde diversas perspectivas como la psicología, la sociología, la educación, la comunicación, la ingeniería informática, la neurociencia... Si bien tiene su punto álgido en el siglo xx a raíz de la evolución de las sociedades capitalistas en la necesidad por explicar el comportamiento de la sociedad, se trata de un ámbito de interés que se consolida hoy día por estar inmerso en la cultura de la imagen.

11 Si tomamos el concepto «emoción» y lo extrapolamos a la esfera de lo digital, Serrano Puche (2016) determina que Internet ayuda a expresar las emociones y a que el sujeto construya su propia subjetividad. En el ámbito de las redes sociales, el autor acentúa el peso del análisis de los sentimientos en estos canales y apunta hacia la necesidad de conocer «el tipo de sentimiento que una persona puede experimentar o intenta expresar al exponerse en este ámbito» (2016: 22); la felicidad, la soledad, la depresión, el miedo, la ira, la alegría, la sorpresa y la tristeza son los sentimientos que más comúnmente se exhiben en las RSD (Peña Acuña \& Rubio Vega, 2013).

Si bien resulta evidente que las redes sociales se han convertido en un nuevo escenario donde las emociones pueden llegar a ser las protagonistas, existe un debate en torno a la expresión de estas en este entorno.

Por un lado, autores como Martínez Rodrigo, Segura García y Sánchez Martín (2011) plantean que «aunque se estén utilizando medios tecnológicos, tanto quien emite como quien recibe el mensaje es un individuo y, por tanto, se mostrarán los rasgos típicos de la comunicación interpersonal; y es ahí donde entran en juego las emociones» (2011: 174). Estos investigadores deducen que las emociones expresadas en estos espacios surgen de la empatía social y apuntan que «la inmediatez, la personalización y la participación, características propias de la interactividad (rasgo inherente a las RSD), son las que desencadenan las emociones» (2011: 186). Así, «las emociones son usadas como recursos en el trabajo identitario del usuario, en un medio, el digital, marcado por la interconectividad y donde la persona no puede reafirmar su concepto del yo sin ser visible para los demás» (Serrano Puche, 2016: 23). Este comportamiento encuentra justificación en la teoría de la autodiscrepancia (Higgins, 1987) o la teoría de las identidades posibles (Markus \& Nurius, 1986), las cuales abordaron el análisis de los yoes posibles, esperados o ideales; lo cual puede constituir la base teórica del comportamiento actual en las RSD. En relación con ello, nos basamos en «el yo relacional» estudiado por Gergen (1991). Según este proceso, el individuo reconoce que 
su yo es producto de la interacción social, por lo que lo construye en una situación concreta y ante una audiencia determinada mediante un proceso selectivo y reflexivo (Haferkamp \& Krämer, 2010; Walther, 2007). Así pues, resulta indiscutible que en el campo digital la dimensión emocional y la manifestación de los estados de ánimo están vinculados con la configuración de la identidad. Si bien Svensson (2014) afirma que en las redes sociales "cuanto más te enlaza la gente, más le da a "me gusta" en tus publicaciones, más la comenta [...] más incrementa el nivel de satisfacción y bienestar personal» (2014: 22), Heredia y García (2017) plantean que las emociones no solo provocan efecto en quien las expone, sino que, al mismo tiempo, el hecho de transmitirlas a través de las redes sociales contribuye a crear un bienestar público, pero también personal. En este sentido, Derks, Fischer y Bos (2008) afirman que la comunicación mediada a través de la tecnología digital se caracteriza por la exposición de emociones positivas y que incluso aquellas que son negativas se expresan más abiertamente en el espacio online que en el offline.

En el plano opuesto se posicionan Sádaba y Bringué (2005) para quienes las emociones no fluyen de la misma manera en una relación expuesta a través de instrumentos tecnológicos (las RSD) que en una relación interpersonal presencial real, lo cual resulta interesante reflexionar desde el punto de vista de los/as usuarios/as jóvenes (niños/as en ocasiones), los cuales están comenzando a desarrollar sus capacidades tanto humanas, como cognitivas y emocionales desde dichas plataformas.

\section{Método}

Esta investigación, de carácter exploratorio y descriptivo, se enmarca en el Proyecto «Produsage juvenil en las redes sociales y manifestación de las desigualdades de género: nuevas formas de violencia» $»^{1}$. La metodología aplicada, de corte cuantitativo, pretende conocer, desde una perspectiva de género, las formas de mostrarse y los estados de ánimo manifestados por los y las jóvenes a través de su representación en WhatsApp. Para ello, se aplica la técnica de la observación no participante. El estudio que aquí se presenta tiene como antecedente directo la investigación de las autoras «Identidades digitales en WhatsApp. La representación del género entre la población universitaria», publicada en 2020 (Vera, Sánchez \& Romo, 2020).

La muestra se compone de 194 estudiantes de ambos sexos, pertenecientes a distintas titulaciones universitarias de las Facultades de Ciencias de la Comunicación de la Universidad de Málaga y Sevilla (grados en Periodismo; Comunicación Audiovisual; y Publicidad) y de los grados en Trabajo Social; Ingeniería Industrial; Geografía y Ciencias de la Educación, de la Universidad de Málaga. El total de la muestra consultada (194 estudiantes) contaba con perfiles definidos, en tanto que solo 161 sujetos mostraban un estado definido en la aplicación WhatsApp.

La selección de la muestra fue intencional, en función de la disponibilidad del alumnado a participar en este estudio y, dada la feminización de muchas de las titulaciones implicadas, el número de mujeres fue mayor que el de hombres, tal y como podemos observar en la tabla 1. 
Tabla 1. - Perfil y estado definidos en función del sexo.

\begin{tabular}{|l|l|l|l|}
\hline & Hombres & Mujeres & Total \\
\hline Imagen definida & $\begin{array}{l}39,2 \% \\
(76)\end{array}$ & $\begin{array}{l}60,8 \% \\
(118)\end{array}$ & $\begin{array}{l}100 \% \\
(194)\end{array}$ \\
\hline Estado definido & $\begin{array}{l}35,4 \% \\
(57)\end{array}$ & $\begin{array}{l}64,6 \% \\
(104)\end{array}$ & $\begin{array}{l}100 \% \\
(161)\end{array}$ \\
\hline
\end{tabular}

Fuente: elaboración propia. categorías que permitieron obtener una información detallada que fue analizada a través del programa Microsoft Excel (versión 365). La validación de dichos indicadores no ofrece dudas, ya que se optó por redactarlos según el sistema binario $\left(s_{1}^{\prime}=1\right.$, no=0). Para su determinación, se recurrió a los estudios previos de Magnuson y Dundes, 2008; De Vries y Peter, 2013; Martín Bonacci, 2013; Basile y Linne, 2014.

\section{Indicador 1. Estado e imagen definida.}

-Ítem 1. Estado definido: el/la estudiante ha recurrido al texto y/o emoticonos para determinar su «estado».

-Ítem 2. Imagen: el/la estudiante ha incluido en su perfil una imagen definida.

Indicador 2. Recursos para generar contenido en el estado de WhatsApp.

-Ítem 1: Texto.

-Ítem 2: Emoticono.

-Ítem 3: Texto más emoticono. 
-Ítem 1. No manifiestan estado de ánimo concreto.

-Ítem 2. Manifiestan tristeza.

-Ítem 3. Manifiestan alegría.

\section{Resultados}

\section{La expresión del estado de ánimo en el estado de WhatsApp}

En lo que concierne al contenido que hallamos en el estado de las y los participantes, la mayoría de ellas y ellos lo cumplimentan a través de texto, aunque aquí las diferencias en función del sexo son ostensibles. En el caso de los alumnos, una gran mayoría $(63,2 \%)$ se expresan a través de texto frente al $44,2 \%$ de las estudiantes. Si bien, como vemos en la tabla 2, para los chicos el orden decreciente en términos porcentuales implica la utilización de texto, seguido de texto y emoticono $\mathrm{y}$, por último, de emoticono; las preferencias en el caso de las mujeres muestran una situación diferente. El orden de importancia para ellas, partiendo de la preferencia por la utilización de texto, se invierte en las dos opciones restantes. Esto es, utilizan más el emoticono que la conjunción entre el texto y el emoticono. En cualquier caso, la distribución entre las tres posibilidades expresadas en la tabla es más equilibrada en el caso de las estudiantes. Es interesante observar que un $34 \%$ de las chicas se mostraban en su estado a través de emoticonos, suponiendo aproximadamente el doble del porcentaje de chicos que optaban por ello.

Tabla 2. - Contenido del estado.

\begin{tabular}{|l|l|l|l|l|}
\hline Estado definido/Sexo & Texto & Emoticono & Texto y emoticono & Total \\
\hline Hombres & $63,2 \%$ & $15,8 \%$ & $21,0 \%$ & $100 \%$ \\
57 & $(36)$ & $(9)$ & $(12)$ & $(57)$ \\
\hline
\end{tabular}




\begin{tabular}{|l|l|l|l|l|}
\hline Mujeres & $44,2 \%$ & $33,7 \%$ & $22,1 \%$ & $100 \%$ \\
104 & $(46)$ & $(35)$ & $(23)$ & $(104)$ \\
\hline
\end{tabular}

Respecto a la demostración del estado de ánimo dentro del estado de WhatsApp, son pocas las personas participantes que lo expresaban claramente: 30 alumnas $(28,9 \%)$ y 11 alumnos (19,3\%). Como podemos ver, esto supone una diferencia de prácticamente 10 puntos porcentuales a favor de una mayor propensión a expresar su estado de ánimo en las mujeres.

30 Además, si relacionamos el estado de ánimo y el contenido del estado (ver tabla 3), observamos que más de la mitad de los hombres lo mostraban a través de texto, en tanto que las mujeres utilizaban en proporción similar el texto y emoticono.

Tabla 3. - Relación entre contenido del estado y estado de ánimo.

\begin{tabular}{|l|l|l|l|l|}
\hline Manifiestan estado de ánimo/Sexo & Texto & Emoticono & Texto y emoticono & Total \\
\hline Hombres & $\begin{array}{l}54,5 \% \\
(6)\end{array}$ & $\begin{array}{l}18,2 \% \\
(2)\end{array}$ & $\begin{array}{l}27,3 \% \\
(3)\end{array}$ & $\begin{array}{l}100 \% \\
(11)\end{array}$ \\
\hline $\begin{array}{l}\text { Mujeres } \\
30\end{array}$ & $\begin{array}{l}26,7 \% \\
(8)\end{array}$ & $\begin{array}{l}(4,3 \% \\
(4)\end{array}$ & $\begin{array}{l}60,0 \% \\
(18)\end{array}$ & $\begin{array}{l}100 \% \\
(30)\end{array}$ \\
\hline
\end{tabular}

\section{La imagen de perfil como reflejo del estado de ánimo}

31 En la tabla 4 podemos ver la forma en que se representan chicas y chicos a través de la imagen de perfil de WhatsApp. Observamos que tanto alumnos como alumnas prefieren representarse individualmente $(54 \%$ y $43 \%$, respectivamente). Respecto a la representación grupal, los chicos se inclinan algo más por utilizar fotografías grupales con personas de otro sexo que sus compañeras. En cualquier caso, si sumamos las representaciones grupales, las alumnas optan más que sus compañeros por representarse de esta manera (un $44 \%$ de ellas frente al $37 \%$ de ellos) y también acuden más a otras imágenes para autodefinirse frente a sus compañeros varones. Claramente, los chicos son más proclives a representarse de manera individual frente a las chicas, que eligen las opciones individual y grupal de forma más homogénea.

Tabla 4. - Imagen del perfil: representación de la(s) persona(s) y otras imágenes.

\begin{tabular}{|l|l|l|l|l|l|}
\hline $\begin{array}{l}\text { Imagen } \\
\text { definida }\end{array}$ & $\begin{array}{l}\text { Persona } \\
\text { individual }\end{array}$ & $\begin{array}{l}\text { Grupal del mismo } \\
\text { sexo }\end{array}$ & $\begin{array}{l}\text { Grupal con otro } \\
\text { sexo }\end{array}$ & $\begin{array}{l}\text { Otras } \\
\text { imágenes }\end{array}$ & Total \\
\hline Hombres & $\begin{array}{l}53,9 \% \\
(41)\end{array}$ & $\begin{array}{l}15,8 \% \\
(12)\end{array}$ & $\begin{array}{l}21,1 \% \\
(16)\end{array}$ & $\begin{array}{l}9,2 \% \\
(7)\end{array}$ & $\begin{array}{l}100 \% \\
(76)\end{array}$ \\
\hline $\begin{array}{l}\text { Mujeres } \\
118\end{array}$ & $\begin{array}{l}43,2 \% \\
(51)\end{array}$ & $\begin{array}{l}21,2 \% \\
(25)\end{array}$ & $\begin{array}{l}22,9 \% \\
(27)\end{array}$ & $\begin{array}{l}12,7 \% \\
(15)\end{array}$ & $\begin{array}{l}100 \% \\
(118)\end{array}$ \\
\hline
\end{tabular}



claramente utilizan más los escenarios exteriores, dado que un $56 \%$ de ellas lo prefiere frente al 31\% que se muestra en espacios interiores. Sin embargo, los estudiantes se muestran en porcentaje similar en ambos escenarios. Por otra parte, y aunque el número absoluto de las personas que se ubican en esta situación es muy exiguo, es interesante hacer notar que las alumnas optan más por utilizar escenarios sin definición concreta que los chicos.

Tabla 6. - Escenario en el que se toma la fotografía.

\begin{tabular}{|l|l|l|l|l|}
\hline Imagen individual+grupal/Sexo & Exterior & Interior & Sin escenario definido & Total \\
\hline $\begin{array}{l}\text { Hombres } \\
69\end{array}$ & $\begin{array}{l}47,8 \% \\
(33)\end{array}$ & $\begin{array}{l}50,7 \% \\
(35)\end{array}$ & $\begin{array}{l}1,5 \% \\
(1)\end{array}$ & $\begin{array}{l}100 \% \\
(69)\end{array}$ \\
\hline $\begin{array}{l}\text { Mujeres } \\
103\end{array}$ & $\begin{array}{l}56,3 \% \\
31,1 \%\end{array}$ & $\begin{array}{l}12,6 \% \\
(32)\end{array}$ & $(13)$ & $\begin{array}{l}100 \% \\
(103)\end{array}$ \\
\hline
\end{tabular}

Resumiendo los comentarios para las tablas 4,5 y 6 , podemos sintetizar las siguientes ideas. Aunque alumnos y alumnas escogen mayoritariamente imágenes individuales para presentarse en su perfil de WhatsApp, los chicos lo prefieren más que sus compañeras, ya que estas comparten esta preferencia con la representación grupal. Por otra parte, fijándonos en general en las fotografías, hay una diferencia ostensible en la postura que adoptan frente a la cámara: ellas prefieren la pose en tanto que hemos visto una mayor tendencia de los estudiantes varones a mostrarse de manera natural. Asimismo, las estudiantes se presentan mayoritariamente en espacios exteriores, en 
tanto que los chicos se reparten de manera más equilibrada entre los escenarios exteriores e interiores.

Tras esta visión panorámica de la forma de representarse en el perfil de WhatsApp, a continuación analizaremos las manifestaciones del estado de ánimo y sus interrelaciones con las variables que acabamos de observar en las tablas 4, 5 y 6 .

Como puede verse en la tabla 7, no se pudo determinar un estado de ánimo concreto en el $60,5 \%$ de los casos de estudiantes varones y en el 39\% de las alumnas. En cualquier caso, cuando lo manifiestan ( 30 chicos y 72 chicas), se representan eminentemente alegres ya que, en función de los resultados, la tristeza no constituye una opción representativa.

Tabla 7. - Imagen del perfil: expresión del estado de ánimo.

\begin{tabular}{|l|l|l|l|l|}
\hline Imagen definida/Sexo & No manifiestan estado de ánimo concreto & Tristeza & Alegría & Total \\
\hline $\begin{array}{l}\text { Hombres } \\
76\end{array}$ & $\begin{array}{l}60,5 \% \\
(46)\end{array}$ & $\begin{array}{l}1,3 \% \\
(1)\end{array}$ & $\begin{array}{l}38,2 \% \\
(29)\end{array}$ & $\begin{array}{l}100 \% \\
(76)\end{array}$ \\
\hline Mujeres & $39,0 \%$ & $0,0 \%$ & $61,0 \%$ & $100 \%$ \\
118 & $(46)$ & $(0)$ & $(72)$ & $(118)$ \\
\hline
\end{tabular}

Si analizamos las expresiones de alegría en base a la manera de representarse (individual, grupal y grupal con otro sexo), según la posición que adoptan (natural o posando) y en función del escenario en el que se ubican, obtenemos los resultados que se desglosan a continuación.

Tabla 8. - Expresión de alegría en función de representación de persona.

\begin{tabular}{|l|l|l|l|l|}
\hline Muestran alegría & Individual & Grupal del mismo sexo & Grupal con otro sexo & Total \\
\hline $\begin{array}{l}\text { Hombres } \\
29\end{array}$ & $\begin{array}{l}31,0 \% \\
(9)\end{array}$ & $\begin{array}{l}24,2 \% \\
(7)\end{array}$ & $\begin{array}{l}44,8 \% \\
(13)\end{array}$ & $\begin{array}{l}100 \% \\
(29)\end{array}$ \\
\hline $\begin{array}{l}\text { Mujeres } \\
72\end{array}$ & $\begin{array}{l}32,0 \% \\
(23)\end{array}$ & $\begin{array}{l}33,3 \% \\
(24)\end{array}$ & $\begin{array}{l}34,7 \% \\
(25)\end{array}$ & $\begin{array}{l}100 \% \\
(72)\end{array}$ \\
\hline
\end{tabular}

Según los datos reflejados en la tabla 8, obtenemos que los alumnos claramente se muestran más alegres cuando aparecen fotografiados en grupos con el otro sexo. Sin embargo, las estudiantes se distribuyen de manera más uniforme entre todas las posibilidades. Esto es, las alumnas están alegres cuando se fotografían junto al personas del otro sexo pero también lo están cuando se muestran en un grupo con otras chicas y cuando se retratan de manera individual, las diferencias son escasas. Es interesante hacer notar que en el caso de los chicos hallamos una distancia de más de 20 puntos porcentuales entre los que están alegres mostrándose con chicas y los que se representan con otros varones. 
Ellas están decididamente más alegres cuando posan (ver tabla 9), en una proporción que triplica sobradamente a las que están alegres en una posición natural. Los chicos, por su parte, y teniendo en cuenta que no contamos con muchos sujetos en este caso, se muestran alegres de manera similar en las dos posturas.

Tabla 9. - Expresión de alegría en función de la postura.

\begin{tabular}{|l|l|l|l|}
\hline Muestran alegría & Natural & Pose & Total \\
\hline $\begin{array}{l}\text { Hombres } \\
29\end{array}$ & $\begin{array}{l}55,2 \% \\
(16)\end{array}$ & $\begin{array}{l}44,8 \% \\
(13)\end{array}$ & $\begin{array}{l}100 \% \\
(29)\end{array}$ \\
\hline Mujeres & $23,6 \%$ & $76,4 \%$ & $100 \%$ \\
72 & $(17)$ & $(55)$ & $(72)$ \\
\hline
\end{tabular}

41 Como vemos en la tabla 10, los alumnos muestran más alegría cuando se ubican en un escenario interior, al contrario que las chicas. Hay una diferencia para ellos de 24,2 puntos porcentuales a favor del ambiente interior, en tanto que la diferencia entre las chicas es similar (23,7 puntos porcentuales) aunque en sentido inverso, inclinándose esta vez por el escenario exterior. También es destacable que haya un $15 \%$ de alumnas que se muestren alegres en escenarios que no están definidos en tanto que no hay ningún chico en esta situación.

Tabla 10. - Expresión de alegría en función del escenario.

\begin{tabular}{|l|l|l|l|l|}
\hline Muestran alegría & Escenario exterior & Escenario interior & Sin escenario definido & Total \\
\hline $\begin{array}{l}\text { Hombres } \\
29\end{array}$ & $\begin{array}{l}37,9 \% \\
(11)\end{array}$ & $\begin{array}{l}62,1 \% \\
(18)\end{array}$ & $\begin{array}{l}0,0 \% \\
(0)\end{array}$ & $\begin{array}{l}100 \% \\
(29)\end{array}$ \\
\hline $\begin{array}{l}\text { Mujeres } \\
72\end{array}$ & $\begin{array}{l}54,2 \% \\
(39)\end{array}$ & $\begin{array}{l}30,5 \% \\
(22)\end{array}$ & $\begin{array}{l}15,3 \% \\
(11)\end{array}$ & $\begin{array}{l}100 \% \\
(72)\end{array}$ \\
\hline
\end{tabular}

\section{Conclusiones}

Los resultados avalan una distribución clara en función de las representaciones de género sustantivadas en el perfil y en estado de la aplicación WhatsApp. Si el perfil apunta mayoritariamente a la identificación mediante imágenes individuales, resultan ser los chicos los que prefieren representarse con sus compañeras. Respecto a la presentación fotográfica, hay una diferencia ostensible en la postura que adoptan frente a la cámara: ellas prefieren la pose mientras que los estudiantes varones se muestran de manera natural reforzando, tal vez, la autenticidad. En lo relativo a los escenarios, las estudiantes se presentan mayoritariamente en espacios exteriores, en tanto que los chicos se reparten de manera más equilibrada entre los espacios exteriores e interiores. En conjunto la distinta manera de presentarse y de circular en el espacio digital resulta compatible con explicaciones que refrendan la diferencia 
entre quienes lo transitan con la misma autonomía y naturalidad que habitan el espacio real y quienes lo hacen desde el rol marcado por el imperativo de complacer la mirada ajena, posando y gestionando un escenario favorable.

Redundantemente, respecto a la mostración del estado de ánimo son las chicas más expresivas a la hora de declarar su alegría, mientras que el $60,5 \%$ de los chicos no identifica su estado de ánimo como si no fuera significativo a la hora de presentarse ante sus interlocutores; además cuando muestran esa alegría suele ser en grupos con otros y otras personas. Este matiz podría interpretarse como la doble mostración sin marca de estado de ánimo para los iguales y expresamente alegres en el contacto con las otras.

En este número que tiene como eje de discusión los «Refugios identitarios digitales» nuestros resultados se alinean con este concepto de refugio entendido como lugar seguro y como espacio de certezas. En un caso como territorio propio donde reafirmar las masculinidades hegemónicas, auténticas, homosociables, desprovistas de afectos. En el otro como espacio favorecido para mostrar la alegría pero, tal vez, como espacio protegido, como posibilidad para mostrar autonómamente los sentimientos todos, incluso la tristeza.

\section{BIBLIOGRAFÍA}

Aladro Vico Eva, Valbuena de la Fuente Felicísimo \& Padilla Graciela (2012), «Redes sociales y jóvenes universitarios españoles: nuevos ejes de socialización», Austral Comunicación, 1(1), 27-40.

ARaque Loreto Yuly Milena, Tirado Mejia Yuliana, Taborda YePES Katherin Yesenia, García Castaño Vanessa \& MiLlÁN OTERo Katy Luz (2018), «¿Identidad verdadera o idealizada? Proyección de la identidad en Facebook», Funlam Journal of Student's Research, 3, 17-30.

BASILE Diego \& LINNE Joaquín (2014), «Performances de autopresentación a través de fotografías digitales. El caso de los adolescentes de sectores populares en Facebook», Cuadernos.Info, 35, 209-217.

CÁceres ZAPATERo Ma Dolores, BRÄNDEle SeÑán Gaspar \& Ruiz SAn Román José A. (2017), «Sociabilidad virtual: la interacción social en el ecosistema digital», Historia y Comunicación Social, 22(1), 233-247.

CAMPBELl Alex (2006), «The search for authenticity: an exploration of an online skinhead newsgroup», New Media and Society, 8(2), 269-294.

CENTRO DE InVESTigaciones SociolóGicas (2016), Barómetro de febrero de 2016, recuperado a partir de <http://www.cis.es/cis/opencm/ES/1_encuestas/estudios/ver.jsp?estudio=14263>.

Cuesta CAMBra Ubaldo \& GASPAR HeRrero Sandra (2013), «Análisis motivacional del uso del smartphone entre jóvenes: una investigación cualitativa», Historia y Comunicación Social, 18, 435-447. 
D’Amico Alicia (1984), «Salud, identidad y socialización. Relaciones con la imagen fotográfica», V.V.A.A. (1984), ¡Es preciso volar! Primer Encuentro Regional sobre la Salud de la Mujer, Bogotá: Ministerio de Salud.

DE LAURETIS Teresa (1989), Technologies of Gender. Essays on Theory, Film and Fiction, Londres: Macmillan Press.

De VRIEs Dian \& Peter Jochen (2013), «Women on Display: The Effect of Portraying the Self Online on Women's Self-objectification», Computers in Human Behavior, 29(4), 1483-1489.

Del Prete Annachiara \& Redon Pantoja Silvia (2020), «Las redes sociales on-line: Espacios de socialización y definición de identidad», Psicoperspectivas, 19(1), 1-11.

DERKS Daantje, FISCHER Agneta \& Bos Arjan (2008), «The Role of Emotions in Computer-mediated Communication: A Review», Computers in Human Behavior, 24(3), 766-785.

Dientin Tobias (2020), «An Agenda for Open Science in Communication», Journal of Communication, 71(1), 1-26.

ECHEBURÚA ODRIOZOLA Enrique (2012), «Factores de riesgo y factores de protección en la adicción a las nuevas tecnologías y redes sociales en jóvenes y adolescentes», Revista española de drogodependencia, 37(4), 435-447.

FERNÁNDEZ RodRíGUeZ Eduardo \& GUTIÉRREZ PEQUEÑo José Miguel (2017), «La socialización de los jóvenes interconectados: experimentando la identidad en la sociedad aumentada», Profesorado. Revista de currículum y formación del profesorado, 21(2), 171-190.

GERGEN Kenneth (1991), The saturated self: dilemmas of identity in contemporary life, Nueva York: Basic Books.

GonZÁLEZ RAMíreZ Teresa \& LóPEZ GRACia Ángela (2018), «La identidad digital de los adolescentes: usos y riesgos de las Tecnologías de la Información y la Comunicación», Revista Latinoamericana de Tecnología Educativa, 17(2), 73-85.

GuZzo Oriana (2019), «Imágenes e identidad en las redes sociales», Actas de las XXXIII Jornadas de Investigacion, SI+Imágenes. Prácticas de investigación y cultura visual, <https:// publicacionescientificas.fadu.uba.ar/index.php/actas/article/view/1284>.

HAFERKAMP Nina \& KRÄMER Nicole (2010), «Creating a digital self. Impression management and impression formation on social networking sites», K. Drotner \& K. C. Schroder (eds), Digital content creation: creativity, competence, critique, Nueva York: Peter Lang, 129-146.

HALL Jeffrey, PENNINGTON Natalie \& LUEDERS Allyn (2013), «Impression management and formation on Facebook: A lens models approach», New Media and Society,16(6), 958-982.

HIGGINS Tory (1987), «Self-discrepancy: A theory relating self and affect», Psychological Review, 94, 319-340.

HoGG Michael \& REID Scott (2006), «Social identity, self-categorization and the communication of group norms», Communication Theory, 16, 7-30.

ILlouz Eva (2009), El consumo de la utopía romántica, Barcelona: Katz.

KEMP Simon (2016), «We are social: Digital in 2016»: <https://wearesocial.com/special-reports/ digital-in-apac-2016> (11 marzo 2021).

LóPEZ CANTOS Francisco (2017), «WhatsApp. Hábitos de uso y construcción de identidad visual con mensajería móvil», ICONO 14 Revista de comunicación y tecnologías emergentes, 15(2), 70-91. 
MAGNUSON Melissa \& DunDES Lauren (2008), «Gender Differences in "Social Portraits" Reflected in MySpace Profiles», Cyberpsychology and Behavior: The Impact of the Internet, Multimedia and Visual Reality on Behavior and Society, 11(2), 239-241.

MARKUS Hazel \& NURIUS Paula (1986), «Posible selves», American Psychologist, 41, 954-969.

MARTÍN BONACCI Juan (2013), «Los jóvenes de perfil: una aproximación a las representaciones corporales de adolescentes y jóvenes usuarios de Facebook», Mª G. Palazo \& P. A. Gómez (eds), Sujetos, miradas, prácticas y discursos. Segundo Encuentro sobre Juventud, Medios e Industrias Culturales, San Miguel de Tucumán: Facultad de Filosofía y Letras, 68-73.

MARTÍNEZ MARTínez Inmaculada José, AgUADo TERRÓN Juan Miguel y TORTAJADA GIMÉNEZ Iolanda (2009), «Movilizad@s: mujer y comunicaciones móviles en España», Feminismo/s (14), 15-34.

HEREDIA Nazareth \& GARCíA Erika (2017), «Posibles riesgos del uso de las redes sociales en adolescentes», Revista de Estudios e Investigación en Psicología y Educación, 13, 6-10.

MarTínez Rodrigo Estrella, Segura García Rosario \& SÁnchez Martín Lourdes (2011), «El complejo mundo de la interactividad: emociones y redes sociales», Revista Mediterránea de Comunicación, 2(1), 171-190.

MORAL JiMÉNEZ Mª de la Villa (2004), «Jóvenes, redes sociales de amistad e identidad psicosocial: la construcción de las identidades juveniles a través del grupo de iguales», Revista Galego-Portuguesa de Psicoloxia e Educación, 9(11), 183-206.

PeÑA AcuÑa Beatriz \& Rubio Vega Mónica (2013), «Gestión de la emoción en la comunicación mediada por ordenador (CMO)», Estudios sobre el Mensaje Periodístico, 19, 905-913.

PERDOMO ReYES Inmaculada (2016), «Género y tecnologías. Ciberfeminismo y construcción de la tecnocultura actual», Revista Iberoamericana de Ciencia, Tecnología y Sociedad-CTS, 11(31), 171-193.

PÉrez ToRres Vanessa, PASTOR Ruiz Yolanda \& ABARRou Ben BoubaKer Sara (2018), «Los youtubers y la construcción de la identidad adolescente», Revista Comunicar, 55, 61-70.

RENAU Vanessa, OBERST Úrsula \& CARBONELL Xabier (2013), «Construcción de la identidad a través de las redes sociales online: una mirada desde el constructivismo social», Anuario de Psicología, 43(2), 159-170.

RUBIO GAÑAN Mikel (2020), La red Instagram. La cuestión de la distorsión de la identidad (Trabajo Fin de Grado), Universidad Pública de Navarra, España.

SABATER FernándeZ Carmen \& Bingen FernándeZ AlCALDE Josu (2015), «No, sin mi móvil. Diferencias de género y uso de las nuevas tecnologías», ICONO 14 Revista de comunicación y tecnologías emergentes, 13(1), 208-246.

SÁDABA Charo \& BRINGUÉ Xavier (2005), Nacidos digitales, una generación frente a las pantallas, Madrid: Rialp.

Segura Alarcón José Gustavo \& Anguita Anguita Matías (2017), Construcción de la identidad social a través del uso de Instagram (Trabajo Fin de Grado), Universidad del Bío-Bío, Chile.

SERRANO PUCHE Javier (2016), «Internet y emociones: nuevas tendencias en un campo de investigación emergente», Revista Comunicar, 46, 19-26.

STRANO Michele (2008), «User descriptions and interpretations of self-presentation through Facebook profile images», Cyberpsychology, 2(2), s.p. 
SVENSSON Jakob (2014), «Power, Identity, and Feeling in Digital Late Modernity: The Rationality of Reflexive Emotion Displays Online», T. Bensky \& E. Fisher (eds), Internet and Emotions, Nueva York: Routledge, 17-32.

TURKLE Sherry (2011), Alone Together, Nueva York: Basic Books.

Vera BALAnZa Teresa, SÁnchez-Labella Martín Inmaculada, \& Romo PARRA Carmen (2020), «Identidades digitales en WhatsApp. La representación del género entre la población universitaria», Anàlisi: Quaderns de Comunicació i Cultura, 62(nº extraordinario), 67-83.

WAJCMAN Judy (2006), El tecnofeminismo, Madrid: Cátedra.

WALTHER Joseph (2007), «Selective self-presentation in computer-mediated communication:

Hyperpersonal dimensions of technology, language and cognition», Computers in Human Behavior, 23, 2538-2557.

ZHAO Shanyang, GRASMUCK Sherri \& MARTIN Jason (2008), «Identity construction on Facebook: Digital empowerment in anchored relationships», Computers in Human Behavior, 24(5), 1816-1836).

\section{NOTAS}

1. «Produsage juvenil en las redes sociales y manifestación de las desigualdades de género: nuevas formas de violencia». FEM2017-83302-C3-2-P, Plan Nacional de I+D+I. España, Ministerio de Economía, Industria y Competitividad, 2018-2021.

\section{RESÚMENES}

Diversos estudios demuestran como la juventud ha encontrado en las redes sociales una vía en la que expresar sus sentimientos y emociones ante otros usuarios y usuarias a los que desconocen. Aunque la literatura científica sobre redes sociales es abundante, este trabajo pone el foco en WhatsApp como aplicación de chat que permite proyectar estados de ánimo bien mediante la fotografía de perfil o bien a través del texto que la acompaña. El objetivo de este trabajo se centra en analizar, desde una perspectiva de género, cómo las y los universitarios utilizan esta aplicación para expresar sus estados de ánimo, en este caso, ante las personas conocidas que conforman su agenda telefónica. Para ello, hemos contado con una muestra de 194 estudiantes de ambos sexos, pertenecientes a distintas titulaciones procedentes de las Facultades de Ciencias de la Comunicación de la Universidad de Málaga y Sevilla. Mediante una metodología de corte cuantitativo, y utilizando como herramienta de abordaje el análisis de contenido, se ha confeccionado una ficha de análisis, la cual nos ha permitido observar las imágenes y recursos empleados para proyectar distintas situaciones anímicas. Tras el análisis de los resultados, se concluye que el escenario digital se presenta como un refugio para la pervivencia de los roles de género, donde las chicas resultan más expresivas de cara a su red de contactos sociales y los chicos refuerzan la naturalidad y el desapego afectivo enfatizando la masculinidad hegemónica.

Several studies show how young people have found in social networks a way to express their feelings and emotions to other users whom they do not know. Although the scientific literature 
on social networks is abundant, this paper focuses on WhatsApp as a chat application that allows users to project moods either through the profile picture or through the text that accompanies it. The aim of this study is to analyse, from a gender perspective, how university students use this application to express their moods, in this case, to the people they know who make up their phonebook. We have used a sample of 194 students of both sexes, belonging to different degrees from the Faculties of Communication Sciences at the University of Malaga and Seville. We applied a quantitative methodology and used content analysis as an approach tool to create an analysis sheet that allowed us to observe the images and resources used to project different emotional situations. After analysing the results, we conclude that the digital scenario is presented as a refuge for the survival of gender roles, where girls are more expressive in terms of their network of social contacts and boys reinforce naturalness and affective disengagement, emphasising hegemonic masculinity.

Plusieurs études montrent comment les jeunes ont trouvé dans les réseaux sociaux un moyen d'exprimer leurs sentiments et leurs émotions à d'autres utilisateurs qu'ils ne connaissent pas. Bien que la littérature scientifique sur les réseaux sociaux soit abondante, cet article se concentre sur WhatsApp, une application de chat qui permet de projeter ses états d'âme soit au moyen de la photo de profil, soit par le texte qui l'accompagne. L'objectif de cette étude est d'analyser, dans une perspective de genre, comment les étudiants utilisent cette application pour exprimer leurs emotions, en l'occurrence, aux personnes qu'ils connaissent et qui composent leur répertoire téléphonique. Nous avons eu un échantillon de 194 étudiants des deux sexes, appartenant à différents parcours universitaires des Facultés des Sciences de la Communication de l'Université de Malaga et de Séville. Nous avons appliqué une méthodologie quantitative et utilisé l'analyse de contenu comme outil d'approche pour créer une fiche d'analyse qui nous a permis d'observer les images et les ressources utilisées pour signifier différentes situations émotionnelles. Après avoir analysé les résultats, nous concluons que le scénario numérique est présenté comme un refuge pour la survie des rôles de genre, où les femmes sont plus expressives envers leur réseau social et où les garçons renforcent le naturel et le détachement affectif qui renforcent la masculinité hégémonique.

ÍNDICE

Keywords: emotions, young people, WhatsApp, digital identities, gender

Palabras claves: emociones, jóvenes, WhatsApp, identidades digitales, género

Mots-clés: émotions, jeunes, WhatsApp, identité visuelle, genre

\section{AUTORES}

\section{CARMEN ROMO PARRA}

Universidad de Málaga

cromo@uma.es

\section{INMACULADA SÁNCHEZ-LABELLA MARTÍN}

Universidad de Sevilla

Isanchez4@us.es 
TERESA VERA BALANZA

Universidad de Málaga

mvb@uma.es 